\title{
Consumer Reported Care Deferrals Due to the COVID-19 Pandemic, and the Role and Potential of Telemedicine: Cross-Sectional Analysis
}

Adam Atherly ${ }^{1}, \mathrm{PhD}$; Eline Van Den Broek-Altenburg ${ }^{2}, \mathrm{PhD}$; Victoria Hart ${ }^{3}, \mathrm{PhD} ;$ Kelsey Gleason ${ }^{3}, \mathrm{PhD} ; \mathrm{Jan}$ Carney $^{3}$, MD

${ }^{1}$ Center for Health Services Research, Larner College of Medicine, University of Vermont, Burlington, VT, United States

${ }^{2}$ Department of Radiology, Larner College of Medicine, University of Vermont, Burlington, VT, United States

${ }^{3}$ Department of Medicine, Larner College of Medicine, University of Vermont, Burlington, VT, United States

\section{Corresponding Author:}

Adam Atherly, $\mathrm{PhD}$

Center for Health Services Research

Larner College of Medicine

University of Vermont

89 Beaumont Avenue

Burlington, VT, 05404

United States

Phone: 18026563555

Email: adam.atherly@med.uvm.edu

\section{Abstract}

Background: The COVID-19 pandemic forced many health systems to proactively reduce care delivery to prepare for an expected surge in hospitalizations. There have been concerns that care deferral may have negative health effects, but it is hoped that telemedicine can provide a viable alternative.

Objective: This study aimed to understand what type of health care services were being deferred during the COVID-19 pandemic lockdown, the role played by telemedicine to fill in care gaps, and changes in attitudes toward telemedicine.

Methods: We conducted a cross-sectional analysis of survey responses from 1694 primary care patients in a mid-sized northeastern city. Our main outcomes were use of telemedicine and reports of care deferral during the shutdown.

Results: Deferred care was widespread - 48\% $(\mathrm{n}=812)$ of respondents deferred care-but it was largely for preventive services, particularly dental and primary care, and did not cause concerns about negative health effects. In total, $30.2 \%(\mathrm{n}=242)$ of those who delayed care were concerned about health effects, with needs centered around orthopedics and surgery. Telemedicine was viewed more positively than prior to the pandemic; it was seen as a viable option to deliver deferred care, particularly by respondents who were over 65 years of age, female, and college educated. Mental health services stood out for having high levels of deferred care.

Conclusions: Temporary health system shutdowns will give rise to deferred care. However, much of the deferrals will be for preventive services. The effect of this on patient health can be moderated by prioritizing surgical and orthopedic services and delivering other services through telemedicine. Having telemedicine as an option is particularly crucial for mental health services.

(JMIR Public Health Surveill 2020;6(3):e21607) doi: 10.2196/21607

\section{KEYWORDS}

COVID-19; telemedicine; deferred care; mental health; alternative; health effect; viability

\section{Introduction}

The COVID-19 pandemic led to an unprecedented worldwide economic and health system shutdown. COVID-19 is caused by the novel SARS-CoV-2, which first emerged in December
2019 in Wuhan, China [1]. As of July 1, 2020, COVID-19 cases have been reported in more than 200 countries with more than half a million confirmed deaths [2]. The first case in Vermont (the region of this study) was reported on March 7, 2020, and the number of cases in Vermont peaked in late April 2020. 
One effect of the pandemic was a widespread temporary shutdown of health care services to prepare the health care system for an expected increase in COVID-19 cases. One unintended consequence of this temporary shutdown is that many types of health care services were deferred until after the "peak" of COVID-19 cases [3-5]. A recent report found that nearly half of all adults reported that either they or someone in their household deferred medical care due to the coronavirus outbreak [6].

As health care systems begin their gradual reopening, the backlog of cases is beginning to be resolved. Yet there is controversy about which services should be reopened and prioritized, with dental care services being a particular flashpoint $[7,8]$. Health care leaders are trying to balance patient needs and the risk of COVID-19 infection as they consider what health care service lines should be prioritized. Yet little is known about what proportion of patients had deferred care during the pandemic or what types of services are most needed from the patient perspective.

Another unintended consequence of the shutdown is the sudden prominence of telemedicine. Telemedicine is not new, but the ability to deliver care remotely without asking patients to increase their risk of infection has brought telemedicine to new prominence during the pandemic. One of the first administrative acts by the Trump administration was to temporarily relax restrictions on telemedicine delivery [9]. Beginning in early March 2020, Medicare began paying for telehealth visits for a broader set of services, locations, modalities, and professions, as well as waiving requirements such as having an established patient-provider relationship [10]. These changes were intended to allow the emergency expansion of telehealth services during the height of the pandemic from April to June 2020.

One approach that can safely deliver nonemergency care can be telemedicine use for routine care. Much of the nonemergency care that occurred during the peak of the crisis was delivered via telemedicine. This created a sudden introduction to telemedicine for both patients and (some) health care professionals. It has been suggested that the pandemic may permanently change the role of telemedicine in America [11], yet whether views on telemedicine have actually changed is unknown.

Our objective was to present the findings from a recent survey of primary care patients in Vermont about both deferred care and telemedicine. We describe for what services care was deferred and where patient concerns about deferred care are highest. We then explore attitudes toward telemedicine, whether those attitudes have changed, and how telemedicine may be used for deferred care if there is another health care system shutdown. Our data were drawn at a unique time to measure care deferral—while it was happening. The results of this study can provide guidance on what is likely to happen in the future if a similar lockdown of health services occurs.

\section{Methods}

The study design is a cross-sectional analysis of the primary care population of the greater Burlington area in Vermont. A random sample of 12,000 individuals over 18 years with at least one primary care visit during the preceding 3 years was drawn from University of Vermont Medical Center patients, stratified by age cohort. Within each 10-year age cohort, a random number generator was used to select the sample. The unit of observation was the individual patient.

Individuals were contacted in two waves between April 30 and May 13, 2020, and asked to consent to participate in the survey. All individuals were provided with an opportunity to opt out of the survey. A total of three follow-up reminders was sent. The survey took an estimated 16-20 minutes to complete and covered a number of different topic areas. These topics included sociodemographic data (eg, age, gender, income, household type and composition, etc), general health status and risk factors (eg, pre-existing health conditions; smoking; COVID-19 symptoms, testing, and diagnosis), exposure to COVID-19 and prevention actions undertaken by the individual, economic impact of the shutdown, beliefs about and preferences for public interventions, telemedicine, and delayed care.

Key variables for our analysis on deferred care included whether the respondent had deferred care due to COVID-19 (yes/no) ("Have you had to defer needed health care because of the COVID-19 outbreak and response?"). For those who answered yes to deferring care, we asked how concerned they were that the delay would harm their health (on a 5-point Likert scale, from very concerned to very unconcerned); we also asked them to specify the type of health service deferred (eg, primary care, dental, oncology, etc). For telemedicine, individuals were asked if they had ever used telemedicine (yes/no), whether they were more or less likely to use telemedicine now versus before the pandemic, and whether they would consider using telemedicine for deferred care.

Key control variables include age (in categories), income (in categories), gender, education (college: yes/no), and presence of chronic illnesses (yes/no from a list including conditions identified by the Centers for Disease Control and Prevention as increasing the risk of COVID-19 complications) [12]. We also included variables indicating whether the person had lost their job due to COVID-19. For those who had an income reduction due to COVID-19, we asked by how much their income had declined.

Means and frequencies from the data were calculated. For our analysis of reasons for deferred care, the denominator is individuals who reported deferring care. For the telemedicine analysis, the denominator is the entire sample. For dichotomous variables (increased interest in telemedicine and willingness to use telemedicine for deferred care), we performed a multivariate analysis using a logit model, with the coefficients calculated as odds ratios. Variables were considered to be statistically significant with a $P$ value $<.05$.

The study was approved by the Institutional Review Board of the University of Vermont. Participants were not compensated for study participation. 


\section{Results}

The initial sample comprised 12,000 individuals. Of these, $11,700(98 \%)$ had a functioning email address. We had a total of 2275 responses (19.4\%), and 1961 (16.3\%) individuals both read the consent form and agreed to participate. Of these, 1694 $(14.1 \%)$ people completed the survey.
Overall, $48 \%$ of the sample (803 out of 1694 completed responses) reported deferring care due to COVID-19. Of these 803 individuals who reported deferred care, $78 \% \quad(n=626)$ reported that the care was deferred due to a cancellation of the appointment by the health care provider rather than due to a decision by the respondent, while in $22 \%(n=177)$ of cases the respondent decided to cancel. The sample was relatively evenly distributed by age (Table 1).

Table 1. Descriptive statistics from the sample of 1681 observations showing frequencies and percentages in different categories.

\begin{tabular}{|c|c|}
\hline Variable & Respondents, n (\%) \\
\hline \multicolumn{2}{|l|}{ Age group (years) } \\
\hline $18-24$ & $62(3.69)$ \\
\hline $25-34$ & $285(16.95)$ \\
\hline $35-44$ & $327(19.45)$ \\
\hline $45-55$ & $365(21.71)$ \\
\hline $55-64$ & $412(24.51)$ \\
\hline $65-75$ & $230(13.68)$ \\
\hline \multicolumn{2}{|l|}{ Income (\$ USD) } \\
\hline Prefer not to answer & $100(5.95)$ \\
\hline$\$ 1000-\$ 25,000$ & $50(2.97)$ \\
\hline$\$ 25,001-\$ 50,000$ & $145(8.63)$ \\
\hline$\$ 50,001-\$ 75,000$ & $241(14.34)$ \\
\hline$\$ 75,001-\$ 100,000$ & $338(20.11)$ \\
\hline$>\$ 100,001$ & $807(48.01)$ \\
\hline \multicolumn{2}{|l|}{ Education } \\
\hline Less than college & $401(23.85)$ \\
\hline College graduate & $1280(76.15)$ \\
\hline \multicolumn{2}{|l|}{ Location } \\
\hline Urban & $501(29.8)$ \\
\hline Semiurban/suburban & $841(50.03)$ \\
\hline Rural & $339(20.17)$ \\
\hline \multicolumn{2}{|l|}{ Live alone } \\
\hline No & $1465(87.15)$ \\
\hline Yes & $216(12.85)$ \\
\hline \multicolumn{2}{|l|}{ Sex } \\
\hline Male & $691(41.11)$ \\
\hline Female & $990(58.89)$ \\
\hline \multicolumn{2}{|l|}{ Presence of chronic illness } \\
\hline No & $765(45.51)$ \\
\hline Yes & $916(54.49)$ \\
\hline
\end{tabular}

The top reported service line for deferred care was dental services, with $27 \%(\mathrm{n}=219)$ of the sample reporting deferred care for dental services (Table 2). Dental care was followed by primary care $(n=183,23 \%)$ and other services $(n=140,18 \%)$.
Considerably fewer respondents reported deferring care for orthopedics $(n=65,8 \%)$, women's health $(n=56,7 \%)$, and radiology/imaging $(n=45,6 \%)$. 
Table 2. Delayed care by service line among 803 survey respondents in Vermont between April 30 and May 13, 2020, who reported deferring care due to the COVID-19 pandemic medical services shutdown.

\begin{tabular}{ll}
\hline Health care service & Respondents, $\mathrm{n}(\%)$ \\
\hline Dental services & $219(27)$ \\
Primary care & $183(23)$ \\
Other & $140(18)$ \\
Orthopedics & $65(8)$ \\
Women's health/obstetrics and gynecology & $56(7)$ \\
Radiology/imaging & $45(6)$ \\
Surgery & $22(3)$ \\
Internal medicine & $20(2)$ \\
Mental health & $17(2)$ \\
Cancer & $10(1)$ \\
Neurology & $10(1)$ \\
Pediatrics & $8(1)$ \\
Cardiovascular & $7(1)$ \\
\hline
\end{tabular}

Overall, 68\% $(n=546)$ of those who deferred care reported that the purpose of the intended services was preventive care (Table $3)$. Only $38 \%(n=305)$ reported deferring care for existing problems and $29 \%$ for newly emergent problems $(n=233)$, which varied across service type. Dental services had the highest level of deferred care overall. Of those who deferred dental care, it had the highest level of deferred care for preventive services $(n=184,84 \%)$ and the lowest level of deferred care for ongoing $(\mathrm{n}=45,21 \%)$ and newly emergent problems $(\mathrm{n}=37,17 \%)$. In contrast, of those who deferred care for surgery, $68 \%(n=15)$ were for newly emergent issues and $45 \%(n=10)$ for ongoing issues. Orthopedics also stands out for high levels of deferred care for newly emergent $(n=33,51 \%)$ and ongoing $(n=41,63 \%)$ care. Note that these percentages do not necessarily add to $100 \%$ because respondents could check multiple categories.

Table 3. Reasons for delayed care, by service line and problem type, among 803 survey respondents in Vermont between April 30 and May 13, 2020, who reported deferring care due to the COVID-19 pandemic medical services shutdown.

\begin{tabular}{llll}
\hline Health care service & $\begin{array}{l}\text { New developed problem, } \mathrm{n} \\
(\%)\end{array}$ & Care for ongoing problems, $\mathrm{n}(\%)$ & Preventive care, $\mathrm{n}(\%)$ \\
\hline Dental services & $37(17)$ & $45(21)$ & $184(84)$ \\
Primary care & $52(29)$ & $56(30)$ & $137(75)$ \\
Orthopedics & $33(51)$ & $41(63)$ & $23(35)$ \\
Women's health/obstetrics and gynecology & $18(32)$ & $21(38)$ & $40(71)$ \\
Radiology/imaging & $14(30)$ & $14(30)$ & $33(74)$ \\
Surgery & $15(68)$ & $10(45)$ & $6(27)$ \\
Internal medicine & $8(40)$ & $10(50)$ & $13(65)$ \\
Mental health & $4(24)$ & $13(76)$ & $7(41)$ \\
Cardiovascular & $3(43)$ & $4(57)$ & $6(86)$ \\
Other & $38(27)$ & $78(55)$ & $80(57)$ \\
Total & $229(29)$ & $309(38)$ & $547(68)$ \\
\hline
\end{tabular}

Overall, most respondents who deferred care reported relatively low levels of concern about the health effects of the delay (Table 4). Overall, only $5.1 \%(n=41)$ of those who deferred care were very concerned about the health effect of the delay, $25.0 \%$ $(\mathrm{n}=201)$ were concerned, $30 \%(\mathrm{n}=241)$ were neutral about the effect, and $40 \%(\mathrm{n}=320)$ were either unconcerned or very unconcerned. However, the level of concern reported by the survey respondents also varied across service lines. The highest level of concern was for mental health services (very concerned / concerned: $n=10,59 \%)$, followed by surgery $(n=12,55 \%)$ and orthopedics $(n=32,50 \%)$. The lowest level of concern was for primary care $(n=35,19 \%)$ and dental services $(n=60,28 \%)$, which were also the most common services for which care was deferred. 
Table 4. Level of concern about care delays overall and by service line among 803 survey respondents in Vermont between April 30 and May 13 , 2020, who reported deferring care due to the COVID-19 pandemic medical services shutdown.

\begin{tabular}{|c|c|c|c|c|c|}
\hline \multirow[t]{2}{*}{ Health care service } & \multicolumn{5}{|c|}{ Level of concern, $\mathrm{n}(\%)$} \\
\hline & Very concerned & Concerned & Neutral & Unconcerned & Very unconcerned \\
\hline Dental services & $4(1.8)$ & $56(25.8)$ & $56(24.9)$ & $79(36.4)$ & $24(11.1)$ \\
\hline Primary care & $7(3.3)$ & $28(15.4)$ & $64(35.2)$ & $62(34.1)$ & $22(12.1)$ \\
\hline Orthopedics & $11(16.9)$ & $21(32.3)$ & $15(23.1)$ & $11(16.9)$ & $7(10.8)$ \\
\hline $\begin{array}{l}\text { Women's health/obstetrics and } \\
\text { gynecology }\end{array}$ & $4(7.1)$ & 11 (19.6) & $23(41.1)$ & $10(17.9)$ & $8(14.3)$ \\
\hline Radiology/imaging & $5(11.6)$ & $11(23.3)$ & $17(37.2)$ & $10(23.3)$ & $2(4.7)$ \\
\hline Surgery & $1(4.6)$ & $11(50.0)$ & $8(36.4)$ & $0(0.0)$ & $2(9.1)$ \\
\hline Internal medicine & $1(5.0)$ & $7(35.0)$ & $5(25.0)$ & $2(10.0)$ & $5(25.0)$ \\
\hline Mental health & $1(5.9)$ & $9(52.9)$ & $3(17.7)$ & $3(17.7)$ & $1(5.9)$ \\
\hline Other & $5(3.6)$ & $35(25.0)$ & $39(27.9)$ & $46(32.9)$ & $15(10.7)$ \\
\hline Total & $42(5.1)$ & $200(25.0)$ & $242(30.0)$ & $229(28.7)$ & $89(11.2)$ \\
\hline
\end{tabular}

Turning to telemedicine, our analysis now includes the entire sample $(\mathrm{N}=1861)$. Overall, a minority of the sample had used telemedicine $(\mathrm{n}=837,45 \%)$, but a strong majority reported that they were more likely to use telemedicine now than before the pandemic ( $\mathrm{n}=1470,79 \%)$ (Table 5). A majority was willing to use it for deferred care $(n=1359,73 \%)$, but those respondents

were much smaller among individuals who actually deferred care. Among those who deferred care and were concerned about the health effect of the deferral, $59 \%(n=189)$ were willing to use telemedicine for the services. Among those who deferred care and were not concerned about the health effect, only 54\% $(\mathrm{n}=261)$ were willing to use telemedicine to resolve the problem.

Table 5. Experience with and willingness to use telemedicine among 1861 survey respondents in Vermont between April 30 and May 13 , 2020.

\begin{tabular}{ll}
\hline Question & Respondents, $\mathrm{n}(\%)$ \\
\hline Have you ever used telemedicine for health care? & $760(46)$ \\
Yes & $921(55)$ \\
No & $1332(79)$ \\
Are you more likely to use telemedicine now than before the pandemic? & $332(20)$ \\
Yes & \\
No & $1226(73)$ \\
Would you consider using telemedicine for deferred care? & $433(26)$ \\
Yes & $130(59)$ \\
No & $331(54)$ \\
For those with deferred care and are concerned about health effects: would you use telemedicine for deferred care? \\
Yes (concerned about health effects) \\
Yes (not concerned about health effects) \\
No (concerned about health effects) \\
No (not concerned about health effects)
\end{tabular}

The logit analysis of factors explaining factors associated with increases in willingness to use telemedicine tells a similar story (Table 6). The odds ratio (OR) for persons willing to use telemedicine who were very concerned/concerned about the health effect of deferred care due to the pandemic was 0.34 $(P=.02)$ compared to those who were neutral or unconcerned/very unconcerned. However, college graduates (OR 2.15, $P<.001$ ) and females (OR 1.73, $P<.001$ ) were more likely to use telemedicine (reference groups: noncollege graduates and males), as were those with a chronic illness (OR 1.4, $P=.009)$ (reference group: no chronic illness). The largest age effect was in the oldest population (persons $\geq 65$ years: OR $2.29, P=.02$ ) (reference group: $<25$ years). By service line, mental health was the service with the largest increase, although the effect was not statistically significant $(P=.12)$. 
Table 6. Logit regression explaining factors predicting increased willingness to use telemedicine among 1861 survey respondents in Vermont between April 30 and May 13, 2020, with coefficients representing percentage point increases.

\begin{tabular}{llllll}
\hline Variable & Odds Ratio & SE & z & $P$ value & $95 \%$ CI \\
\hline Had deferred care & 0.341 & 0.251 & -1.460 & .143 & $0.081-1.439$ \\
Concerned / very concerned about deferred care & 0.629 & 0.123 & -2.370 & .018 & $0.429-0.922$
\end{tabular}

Age group (years) (reference: 18-24 years)

$\begin{array}{llllll}25-34 & 1.439 & 0.474 & 1.100 & .269 & 0.754-2.744 \\ 35-44 & 1.732 & 0.576 & 1.650 & .099 & 0.902-3.325 \\ 45-54 & 1.571 & 0.518 & 1.370 & .171 & 0.823-2.998 \\ 55-64 & 1.589 & 0.513 & 1.440 & .151 & 0.845-2.990 \\ \geq 65 & 2.290 & 0.814 & 2.330 & .020 & 1.141-4.595\end{array}$

Income (reference: $>\$ 100,001)$

Prefer not to answer
$\$ 1000-\$ 25,000$
$\$ 25,001-\$ 50,000$
$\$ 50,001-\$ 75,000$
$\$ 75,001-\$ 100,000$

College graduate

Income decline (reference: no income decline)

Less than $25 \%$
$50 \%$
$75 \%$
$100 \%$ (I have lost all my income)

Currently unemployed

Location (reference: urban area)

Semiurban/suburban
Rural
Sex: female
Live alone
Have chronic illness

\section{Deferred care in}

Orthopedics
Mental health
Neurology
Pediatrics
Radiology/imaging
Surgery
Primary care
Cancer
Cardiovascular
Internal medicine
Women's health/obstetrics and gynecology
Dental services
Other

$\begin{array}{lllll}0.375 & 0.091 & -4.030 & <.001 & 0.232-0.604 \\ 1.017 & 0.386 & 0.040 & .965 & 0.484-2.138 \\ 1.251 & 0.332 & 0.840 & .400 & 0.743-2.104 \\ 0.994 & 0.205 & -0.030 & .976 & 0.664-1.488 \\ 0.716 & 0.119 & -2.010 & .045 & 0.517-0.992 \\ 2.146 & 0.309 & 5.300 & <.001 & 1.618-2.846\end{array}$

$\begin{array}{lllll}1.069 & 0.196 & 0.360 & .718 & 0.746-1.531 \\ 0.816 & 0.200 & -0.830 & .409 & 0.505-1.321 \\ 0.845 & 0.372 & -0.380 & .703 & 0.357-2.003 \\ 1.446 & 0.505 & 1.060 & .291 & 0.729-2.866 \\ 0.871 & 0.171 & -0.700 & .482 & 0.594-1.279\end{array}$

$\begin{array}{lllll}1.203 & 0.176 & 1.270 & .205 & 0.904-1.602 \\ 1.287 & 0.235 & 1.380 & .168 & 0.899-1.840 \\ 1.727 & 0.225 & 4.200 & <.001 & 1.339-2.229 \\ 0.748 & 0.144 & -1.510 & .131 & 0.513-1.091 \\ 1.400 & 0.181 & 2.600 & .009 & 1.086-1.804\end{array}$

$\begin{array}{lllll}2.810 & 2.230 & 1.300 & .193 & 0.593-13.309 \\ 4.647 & 4.561 & 1.570 & .117 & 0.679-31.812 \\ 1.455 & 1.489 & 0.370 & .714 & 0.196-10.808 \\ 0.963 & 1.004 & -0.040 & .971 & 0.125-7.439 \\ 2.600 & 2.143 & 1.160 & .247 & 0.517-13.083 \\ 3.534 & 3.314 & 1.350 & .178 & 0.562-22.211 \\ 2.688 & 2.016 & 1.320 & .188 & 0.618-11.692 \\ 2.540 & 2.754 & 0.860 & .390 & 0.303-21.268 \\ 4.071 & 5.400 & 1.060 & .290 & 0.303-54.792 \\ 1.940 & 1.729 & 0.740 & .457 & 0.338-11.132 \\ 2.562 & 2.067 & 1.170 & .244 & 0.527-12.458 \\ 2.372 & 1.768 & 1.160 & .247 & 0.550-10.223 \\ 3.830 & 2.934 & 1.750 & .080 & 0.853-17.188\end{array}$


These results are consistent with factors associated with a willingness to use telemedicine for deferred care (Table 7). In this model, having actually deferred care has a strong negative association with willingness to use telemedicine for deferred care $(b=0.18, P=.02)$, but the level of concern was not significantly related. This model again shows a strong age effect, with the $45-55,55-64$, and $\geq 65$ age groups all showing ORs significantly greater than 1 versus the reference group $(<25$ years), with the largest coefficient observed in the $\geq 65$ years group. College graduates, females, and persons with chronic illnesses again had a higher odds, although some of the coefficients were only marginally significant. Location (suburban) was statistically significant (OR 1.42, P=.02) and positive compared to urban although rural was not. 
Table 7. Logit regression explaining factors predicting willingness to use telemedicine for deferred care among 1861 survey respondents in Vermont between April 30 and May 13, 2020 with coefficients representing percentage point increases.

\begin{tabular}{llllll}
\hline Variable & Coefficient & SE & $\mathrm{z}$ & $P$ value & $95 \%$ CI \\
\hline Had deferred care & 0.183 & 0.135 & -2.290 & .022 & $0.043-0.781$ \\
Concerned / very concerned about deferred care & 0.856 & 0.144 & -0.930 & .353 & $0.616-1.189$
\end{tabular}

Age group (years) (reference: 18-24 years)

$\begin{array}{ll}25-34 & 1.211 \\ 35-44 & 2.048 \\ 45-54 & 2.241 \\ 55-64 & 2.328 \\ \geq 65 & 2.802\end{array}$

Income (reference: >\$100,001)

Prefer not to answer
$\$ 1000-\$ 25,000$
$\$ 25,001-\$ 50,000$
$\$ 50,001-\$ 75,000$
$\$ 75,001-\$ 100,000$

College graduate

Income decline (reference: no income decline)

Less than $25 \%$
$50 \%$
$75 \%$
$100 \%$ (I have lost all my income)

Currently unemployed

Location (reference: urban area)

Semiurban/suburban
Rural

Sex: female

Live alone

Have chronic illness

\section{Deferred care in}

Orthopedics
Mental health
Neurology
Pediatrics
Radiology/imaging
Surgery
Primary care
Cancer
Cardiovascular
Internal medicine
Women's health/obstetrics and gynecology
Dental services
Other

1.421

0.955

1.270

1.131

1.218

0.998

4.551

0.788

1.328

0.699

0.545

1.840

0.996

0.930

1.654

1.032

0.538

1.005

$\begin{array}{lll}0.400 & 0.580 & .562 \\ 0.682 & 2.150 & .031 \\ 0.747 & 2.420 & .015 \\ 0.762 & 2.580 & .010 \\ 0.989 & 2.920 & .004\end{array}$

$0.634-2.312$

1.066-3.934

1.166-4.306

1.226-4.420

1.403-5.596

0.409-1.156

0.513-2.422

0.591-1.535

$0.597-1.262$

0.694-1.328

0.975-1.753

0.610-1.193

0.507-1.300

0.274-1.281

0.570-2.038

0.667-1.418

$\begin{array}{lll}0.187 & -0.140 \quad .885\end{array}$

1.071-1.887

0.680-1.342

0.987-1.635

0.771-1.662

0.952-1.559

$\begin{array}{lll}0.630 & .529 & 0.771-1.662 \\ 1.570 & .117 & 0.952-1.559\end{array}$

0.153

0.777

$0.000 \quad .998$

$0.217-4.591$

4.483

1.540

.124

0.660-31.373

$-0.240 \quad .809$

0.114-5.454

0.173-10.176

1.380

$0.270 \quad .785$

$0.147-3.330$

$-0.450 \quad .653$

$0.102-2.925$

0.467

$-0.710$

.479

$0.422-8.023$

1.382

0.810

.417

$0.144-6.894$

1.003

0.000

.997

$0.113-7.688$

$-0.070 \quad .947$

0.291-9.395

1.466

0.570

.570

$0.222-4.810$

0.811

$0.040 \quad .968$

$0.124-2.321$

0.401

$-0.830$

.406

$0.229-4.407$ 


\section{Discussion}

The COVID-19 pandemic created an immediate problem with patients being unable to access care as they normally would, but it also presented an opportunity for telemedicine. In terms of how much of a problem deferred care is, our data present a nuanced interpretation. On the one hand, nearly half the sample deferred care, suggesting that deferred care is a substantial problem. On the other hand, respondents were highly unconcerned about the health effect associated with care deferral and report that it was largely for preventive care, with preventive dental services being the top deferred service. However, there was a subgroup - about a quarter of those who deferred care-who were very concerned about the health effects of the deferral; this group was more likely to defer care in areas like surgery and orthopedics.

Telemedicine has still not been used by the majority of the sample, but respondents indicated a strongly increased willingness to try, particularly for deferred care. This effect was especially significant in older females and more educated respondents, but lower for persons who actually had deferred care. A recent review of barriers to telemedicine adoption identified the top six barriers as technically challenged staff $(11 \%)$, resistance to change $(8 \%)$, cost $(8 \%)$, reimbursement $(5 \%)$, patient age $(5 \%)$, and level of education of the patient (5\%) [13]. The pandemic may have loosened resistance to change, while policy changes altered cost and reimbursement issues. Our findings suggest that age may be less of a factor than suggested by previous research; this is likely due to the lack of alternatives for older persons to receive needed care. This suggests the potential for a permanent shift to telemedicine, assuming reimbursement policies remain in place.

We examined deferred care in the context of an unusual circumstance-the COVID-19-related medical care shutdown. Previous research on deferred care has tended to focus on particular locations such as the emergency room [14], specific populations such as Medicaid enrollees [15] or lower income persons [16], or even particular countries [17]. None of these examples are fully analogous to the situation reported in this paper, where widespread care deferral is seen in a higher income country. The applicability of these findings is most relevant to other high-income countries facing broad pandemic-related shutdowns.

This study has a number of potential limitations. First, the study sample is the primary care population of the Burlington area, and the study was conducted in late March / early April of 2020. The location is a semiurban area with limited racial diversity, extremely high insurance coverage, and relatively high levels of internet access and education. Generalizing to other locations, including other countries and areas that are either more or less urban should be done with caution. The survey was also (purposely) conducted during a time when usual medical care was unavailable. Whether the sentiments expressed in this survey would be true in the future is unknown. The sample also was already engaged to some extent with the health care system (at least one visit in the previous 3 years), so individuals without contact with the health care system may react differently. Finally, the sample was somewhat more educated, wealthier, and comprised more females than the overall population, with $48 \%$ of the sample reporting an income of over $\$ 100,000$ and $76 \%$ having completed college. This somewhat reflects the community, which tends have both a higher income and more education than the United States as a whole [18].

Given the variation in COVID-19 impact across the United States and uncertainties about pandemic duration and potential new waves of infection, our data support potential increased use of telemedicine to support access to health care. We observed evidence of increased acceptance, particularly among older and female respondents. Mental health services had a high level of deferred ongoing care and a high willingness to resolve care deferral through telemedicine. This presents an opportunity for health systems as they prepare for a potential second wave. Additionally, our findings suggest that the pandemic may have permanently changed consumers' willingness to use telemedicine for health care, particularly among older individuals. This newfound acceptance of telemedicine, coupled with insurers' decision to continue reimbursing telemedicine at levels consummate with in-person care, suggest that higher levels of telemedicine in health care may be an enduring change.

\section{Conflicts of Interest}

JC is the author of and receives annual royalties from the textbook Controversies in Public Health and Health Policy, Jones \& Bartlett Learning, 2016.

\section{References}

1. Wiersinga W, Rhodes A, Cheng A, Peacock S, Prescott H. Pathophysiology, Transmission, Diagnosis, and Treatment of Coronavirus Disease 2019 (COVID-19): A Review. JAMA 2020 Jul 10;19:A. [doi: 10.1001/jama.2020.12839] [Medline: 32648899]

2. Coronavirus Resource Center. Johns Hopkins University. URL: https://coronavirus.jhu.edu/data/mortality [accessed 2020-07-15]

3. Willan J, King AJ, Djebbari F, Turner GDH, Royston DJ, Pavord S, et al. Assessing the impact of lockdown: Fresh challenges for the care of haematology patients in the COVID-19 pandemic. Br J Haematol 2020 Jun 23;189(6):e224-e227 [FREE Full text] [doi: 10.1111/bjh.16782] [Medline: 32369622]

4. Tapper EB, Asrani SK. The COVID-19 pandemic will have a long-lasting impact on the quality of cirrhosis care. J Hepatol 2020 Aug;73(2):441-445 [FREE Full text] [doi: 10.1016/j.jhep.2020.04.005] [Medline: 32298769] 
5. Boettler T, Newsome PN, Mondelli MU, Maticic M, Cordero E, Cornberg M, et al. Care of patients with liver disease during the COVID-19 pandemic: EASL-ESCMID position paper. JHEP Rep 2020 Jun;2(3):100113 [FREE Full text] [doi: 10.1016/j.jhepr.2020.100113] [Medline: 32289115]

6. Hamel L, Kearney A, Kirzinger A, Lopes L, Muñana C, Brodie M. Health Tracking Poll - May 2020. KFF. 2020 May. URL: https://www.kff.org/coronavirus-covid-19/report/kff-health-tracking-poll-may-2020/ [accessed 2020-06-03]

7. Guidance for Dental Settings Interim Infection Prevention and Control Guidance for Dental Settings During the COVID-19 Response. Centers for Disease Control and Prevention. 2020 Aug. URL: https://www.cdc.gov/coronavirus/2019-ncov/hcp/ dental-settings.html [accessed 2020-06-03]

8. Ather A, Patel B, Ruparel NB, Diogenes A, Hargreaves KM. Coronavirus Disease 19 (COVID-19): Implications for Clinical Dental Care. J Endod 2020 May;46(5):584-595 [FREE Full text] [doi: 10.1016/j.joen.2020.03.008] [Medline: 32273156]

9. Coronavirus Waivers \& Flexibilities. Center for Medicare and Medicaid Service. 2020. URL: https://www.cms.gov/ about-cms/emergency-preparedness-response-operations/current-emergencies/coronavirus-waivers [accessed 2020-06-03]

10. Medicare Telemedicine Health Care Provider Fact Sheet. Center for Medicare and Medicaid Service. 2020 Mar. URL: https://www.cms.gov/newsroom/fact-sheets/medicare-telemedicine-health-care-provider-fact-sheet [accessed 2020-06-03]

11. Wosik J, Fudim M, Cameron B, Gellad ZF, Cho A, Phinney D, et al. Telehealth transformation: COVID-19 and the rise of virtual care. J Am Med Inform Assoc 2020 Jun 01;27(6):957-962 [FREE Full text] [doi: 10.1093/jamia/ocaa067] [Medline: 32311034]

12. People with Certain Medical Conditions. Centers for Disease Control and Prevention. 2020. URL: $\underline{\text { https://www.cdc.gov/ }}$ coronavirus/2019-ncov/need-extra-precautions/people-with-medical-conditions.html [accessed 2020-07-24]

13. Scott Kruse C, Karem P, Shifflett K, Vegi L, Ravi K, Brooks M. Evaluating barriers to adopting telemedicine worldwide: A systematic review. J Telemed Telecare 2016 Oct 16;24(1):4-12. [doi: 10.1177/1357633x16674087]

14. Washington DL, Stevens CD, Shekelle PG, Henneman PL, Brook RH. Next-day care for emergency department users with nonacute conditions. A randomized, controlled trial. Ann Intern Med 2002 Nov 05;137(9):707-714. [doi: 10.7326/0003-4819-137-9-200211050-00005] [Medline: 12416944]

15. Sommers BD, Baicker K, Epstein AM. Mortality and Access to Care among Adults after State Medicaid Expansions. N Engl J Med 2012 Sep 13;367(11):1025-1034. [doi: 10.1056/nejmsa1202099]

16. Magge H, Cabral HJ, Kazis LE, Sommers BD. Prevalence and predictors of underinsurance among low-income adults. J Gen Intern Med 2013 Sep 1;28(9):1136-1142 [FREE Full text] [doi: 10.1007/s11606-013-2354-z] [Medline: 23371419]

17. Johansson K, Robberstad B, Norheim OF. Further benefits by early start of HIV treatment in low income countries: survival estimates of early versus deferred antiretroviral therapy. AIDS Res Ther 2010 Jan 16;7(1):3 [FREE Full text] [doi: 10.1186/1742-6405-7-3] [Medline: 20180966]

18. QuickFacts: Burlington City, Vermont. United States Census Bureau. URL: https://www.census.gov/quickfacts/ burlingtoncityvermont [accessed 2020-06-03]

\title{
Abbreviations
}

OR: odds ratio

\author{
Edited by T Sanchez; submitted 18.06.20; peer-reviewed by V Strotbaum, A Khoja; comments to author 08.07.20; revised version \\ received 29.07.20; accepted 13.08.20; published 14.09.20 \\ Please cite as: \\ Atherly A, Van Den Broek-Altenburg E, Hart V, Gleason K, Carney J \\ Consumer Reported Care Deferrals Due to the COVID-19 Pandemic, and the Role and Potential of Telemedicine: Cross-Sectional \\ Analysis \\ JMIR Public Health Surveill 2020;6(3):e21607 \\ URL: http://publichealth.jmir.org/2020/3/e21607/ \\ doi: $10.2196 / 21607$ \\ PMID: 32833661
}

(CAdam Atherly, Eline Van Den Broek-Altenburg, Victoria Hart, Kelsey Gleason, Jan Carney. Originally published in JMIR Public Health and Surveillance (http://publichealth.jmir.org), 14.09.2020. This is an open-access article distributed under the terms of the Creative Commons Attribution License (https://creativecommons.org/licenses/by/4.0/), which permits unrestricted use, distribution, and reproduction in any medium, provided the original work, first published in JMIR Public Health and Surveillance, is properly cited. The complete bibliographic information, a link to the original publication on http://publichealth.jmir.org, as well as this copyright and license information must be included. 